\title{
Measures for Mitigating the Effects of Climate Change on Crop Production in Nigeria
}

\author{
D. A. Alawa' ${ }^{1}$, V. C. Asogwa ${ }^{2}$, C. O. Ikelusi ${ }^{3}$ \\ ${ }^{1}$ Department of Vocational and Special Education, University of Calabar, Calabar, Nigeria \\ ${ }^{2}$ Department of Agricultural Education, University of Agriculture, Makurdi, Nigeria \\ ${ }^{3}$ Department of Vocational Teacher Education, University of Nigeria, Nsukka, Nigeria \\ Email: asovinchidi@yahoo.com
}

Received 25 November 2013; revised 21 December 2013; accepted 16 January 2014

Copyright (C) 2014 by authors and Scientific Research Publishing Inc.

This work is licensed under the Creative Commons Attribution International License (CC BY). http://creativecommons.org/licenses/by/4.0/

(c) (i) Open Access

\begin{abstract}
This paper examined the causes, effects and measures for mitigating climate change to ensure adequate supply of food through crop production to address the food insecurity which has occupied a central focus of the Nigerian economy. Unfortunately, crop production is fraught with many ecological challenges including climate change. This climate change which occurs as a result of the buildup of Green House Gases (GHGs) occasioned by industrialization, technological modeling and agriculture, exert significant effects on crop yield, water availability, ecosystem disequilibrium resulting in cases of drought, flood earthquake among others. For crop production to be scaled-up to meet the food requirement of the ever growing Nigerian population amidst these challenges, there is need to mitigate these adverse effects of climate change through the adoption of sustainable land management practices that can reduce the atmospheric stock of GHGs such as zero-tillage, appropriate use of fertilizers, avoidance of bush burning, graze land management, improved water management among others. Achieving great success in these areas requires that Nigerian government should be more proactive in their policies that hold promise for sustainable cultures in agricultural production as well as evolving global partnerships on ecological issues.
\end{abstract}

\section{Keywords}

Climate Change, Green House Gases, Global Warming, Mitigation, Crop Production, Food Insecurity

\section{Introduction}

Agriculture is a major activity that is essential for human survival as it produces basic commodities for society,

How to cite this paper: Alawa, D.A., Asogwa, V.C. and Ikelusi, C.O. (2014) Measures for Mitigating the Effects of Climate Change on Crop Production in Nigeria. American Journal of Climate Change, 3, 161-168.

http://dx.doi.org/10.4236/ajcc.2014.32015 
provides food for people and gainful employment for the majority of Nigerians. The past decades have witnessed a dramatic change in agriculture with food production soaring due to Green Revolution which entailed the use of improved technologies (particularly the breeding of high yielding food crop varieties), the expansion of irrigation, mechanization, specialization and the use of chemical fertilizers and pesticides [1]. While the revolution led to dramatic increase in production especially in Asia and Latin America in the 1960s, the increase was not sustainable. For example, evidence indicates that rice yield growth in Asia declined sharply in the 1980s, from an annual growth rate of $2.6 \%$ in the 1970 s to $1.5 \%$ during the period beginning in 1981 owing partly to increasing prices of chemical fertilizers and agrochemicals [2]. Unfortunately, despite the productivity gains associated with the Green Revolution, poverty and hunger persist while land degradation and agriculture driven environmental damages are prevalent and unabated. These problems are aggravated with population explosion and agricultural intensification in developing countries. Reference [3] estimated that about 848 million people suffered from chronic hunger worldwide between 2003 and 2005, 98\% of which lived in developing countries. To address the food requirements of developing countries in general and Nigeria in particular, there is need to address land degradation and other ecological challenges amongst which is global climate change.

Climate change is a complex phenomenon which became a global issue from the mid to late 20th century onwards. Reference [4] described climate change as a change in global or regional climate patterns which is attributed to the increased levels of atmospheric carbon dioxide produced by the use of fossil fuels. Reference [5] viewed climate change as a short-term or long-term alteration of the statistical properties of a climate system. Such a change can be temporary or permanent, regional or global. Global climate change occurs as a result of the accumulation of emitted GHGs to levels that the atmosphere is warmed up. Reference [6] attributed the major causes of this warming to the rising stocks of GHGs in the atmosphere including carbon dioxide $\left(\mathrm{CO}_{2}\right)$, methane $\left(\mathrm{CH}_{4}\right)$, nitrous oxide $\left(\mathrm{N}_{2} \mathrm{O}\right)$, chloro and fluoro-carbons and a number of other gases that arise from industrial processes. Reference [7] estimated the current stock of greenhouse gases in the atmosphere at 430 parts per million (ppm) of carbon dioxide compared to $280 \mathrm{ppm}$ before the industrial revolution. The author predicted that by the end of 2035, there would be a $2^{\circ} \mathrm{C}$ increase in temperature if nothing is done to address the problem. Climate change has the potential to damage irreversibly the natural resource base on which agriculture depends with grave consequences for food security, hence, the need to change the current practices to adapt to and mitigate the problems of climate change in order to address food insecurity in Nigeria.

According to [8], food insecurity exists when all people at all times do not have access to sufficient, safe, nutritious food to maintain a healthy and active life. It includes lack of physical and economic access to food that meets people's dietary needs as well as their preferences. Food insecurity as a result of the cultivation of depleted soils and other ecological challenges has become a major issue of discourse in Nigeria. Recently, farm lands, household properties, economic trees were lost to flood in 11 states in the country. This flood which is a consequence of climate variability left over 10,000 Nigerians into famine, poverty, death, homelessness and attendant health hazards. Furthermore, the hazard had a multiplier effect on the educational sector as schools were shut down and used as interim camps for victims thus jeopardizing the academic progress of these students in the affected areas. This implies that climate change does not only affect food production but also social, political, economic and educational spheres of the society. If crop production as an aspect of agriculture must thrive on a sustainable basic to the issue of food security, there is immediate need to break into this chain of causation and adequate measures positioned to mitigate the catastrophe associated with climate change.

Mitigation, according to [9] is a response strategy to global climate change which involves the adoption of measures that reduce the amount of emissions (abatement) or enhance the absorption capacity of GHGs (sequestration). The authors explained that the total global potential for mitigation depends on many factors including emission levels, availability of technology, enforcement and incentives. However, before one should look at the mitigation measures, it is necessary to identify the causes, the effects on crop production to value the need to adopt measures for mitigating climate change. Therefore, this paper examines the:

1) Causes of climate change in Nigeria.

2) Effects of climate change on crop production in Nigeria.

3) Relationship between climate change and crop production, and

4) Measures for mitigating climate change challenges to address the food needs of Nigeria.

\section{Causes of Global Climate Change}

Climate change occurs as a result of an increase in the concentration of greenhouse gases (GHGs) like $\mathrm{CO}_{2}, \mathrm{~N}_{2} \mathrm{O}$ 
and $\mathrm{CH}_{4}$. Increased GHGs are associated with economic activities particularly as related to energy, industry, transport and pattern of land use (agricultural production and deforestation). Agricultural activities including land use change and forestry (LUCF) account for nearly one-third of global emissions [10]. Emissions from agricultural sector are primarily $\mathrm{CH}_{4}$ and $\mathrm{N}_{2} \mathrm{O}$ making the sector the largest producer of non- $\mathrm{CO}_{2}$ emissions. While agriculture also generates very large $\mathrm{CO}_{2}$ fluxes (both to and from the atmosphere via photosynthesis and respiration), these are nearly balanced on existing agricultural lands. Significant carbon releases, however, results from the conversion of forested land and other GHGs emission arising from agricultural activities such as those relating to (upstream) manufacture of equipment, fertilizers and pesticides, and on-farm use of fuels and transportation of agricultural products. Thus, emission from agriculture come from four principal sectors: agricultural soils, livestock and manure management, rice cultivation and burning of agricultural residues and savanna for land clearing.

Nitrous oxide $\left(\mathrm{N}_{2} \mathrm{O}\right)$ is the largest source of GHG emission from agriculture and accounts for 38 percent of the total global share. $\mathrm{N}_{2} \mathrm{O}$ is produced naturally in soils through the process of nitrification and denitrification. Agricultural activities may add nitrogen to the soil either directly or indirectly. Direct additions occur through nitrogen fertilizer usage, application of managed livestock manure and sewage sludge, production of nitrogen fixing crops and forages, retention of crop residues and cultivation of soils with high organic matter content. Indirect additions occur through volatilization and subsequent atmospheric deposition of applied nitrogen as well as through surface run off and leaching of applied nitrogen into ground water and surface water [11]. These processes have potentials to increase $\mathrm{N}_{2} \mathrm{O}$ emission and contribute to climate variability.

Enteric fermentation or the natural digestive processes in ruminants such as cattle and sheep accounts for the majority of methane production in this category. Reference [9] reported that it is the second largest source of total emission of $\mathrm{CH}_{4}$ from agriculture with a 34 percent global share. Other domesticated animals such as swine, poultry and horses also emit methane as a by-product of post enteric fermentation (fermentation in the caecum). Furthermore, manure management which includes the handling, storage and treatment of manure accounts for 7 percent of agricultural emission. Methane is produced by the anaerobic breakdown of manure while nitrous oxide results from handling manure aerobically (nitrification) and then anaerobically (denitrification) thus contributing to the global buildup of $\mathrm{CH}_{4}$ and $\mathrm{N}_{2} \mathrm{O}$.

Flooded rice fields are the third largest source of agricultural emission and contribute about 11 percent of $\mathrm{CH}_{4}$ which arises from anaerobic decomposition of organic matter.

Similarly, the traditional farming practice of setting fire on agricultural lands and other residues which is a regular farming practice among Nigerian farmers contributes greatly to the emission stock of $\mathrm{CO}_{2}, \mathrm{CH}_{4}$ and $\mathrm{N}_{2} \mathrm{O}$ and increase climate change problems.

The emissions of GHGs from human activities, no doubts, have influence on global climate change. As a result, the question is no longer whether humans are altering the world's climate but where, when and by how much. Thus, it has become obvious that to prevent the onset of catastrophic changes to the earth climate, humans should be aware of the effects of climate change on human, water, animal and crop production.

\section{Effects of Climate Change on Crop Production}

Although climate change may result in some benefits such as extended growing season or more moderate temperature in some areas, the overall effects are likely to be harmful.

The worldwide redistribution of disease vectors, that is, the animals, insects, microorganisms and plants that transmit diseases which are already upon Nigeria, could increase due to climate change. Currently, many tropical diseases of crops, severe pest attacks and weeds are common and contribute to reduction in yields of crops. Crops that are excellent competitors under stable environmental conditions often cannot survive when their habitat is altered by rapid change. Instead parasitic species such as weeds, rodents, insects, bacteria and viruses will quickly reproduce and colonize the disturbed environment. The buildups of these organisms have adverse effect on crop yields and food supply.

Nigeria is highly vulnerable to climate change with areas of particular concern being water resources, agriculture, health ecosystem and biodiversity, forestry and coastal zones. The long-term effects will include changing rainfall patterns which affect agriculture and reduce crop yields. Reference [6] stated that climate change has potentials to worsen water security, economic growth prospects, shifting temperature, and more challenging hurdles in reaching the Millennium Development Goals (MDGs). Reference [12] reported that the cost of adap- 
tation in Africa could be as high as 5\% to $10 \%$ of the continent's GDP. Nigeria as a country under African continent is not exempted from this problems.

Agriculture and food security are at stake as over 95\% of Africa's agriculture is rain-fed [12]. Agricultural production, including access to food in many African countries including Nigeria and sub-regions is projected to be severely compromised by climate change. The areas suitable for agriculture, length of growing seasons and yield potentials, particularly along the margins of semi-arid and arid area are expected to decrease. This would adversely affect food security and exacerbate malnutrition in the continent in some countries and yields from rain-fed agriculture could be reduced by up to 50 percent.

Furthermore, [13] revealed that climate change and its effects could irreversibly damage the natural resource base on which crop production depends. The organization explained that extreme climate events (flood and drought) are increasing and are likely to adversely affect food crop and forestry production. These scenarios are currently beseeching Nigerian Agriculture (especially food crop cultivation) as cases of food insecurity persists following flood incidences experienced in the country recently.

A critical analysis of the consequences of climate change on food crop production reveals that it is less desirable, though there is relationship between crop production and climate change.

\section{Relationship between Crop Production and Climate Change}

Crop production activities rely on operations such as clearing, tillage, application of manure/fertilizer, pesticides and use of machines and other equipment. These operations which are necessary to achieve the goal of crop production in order to meet the food needs of Nigerians contribute substantial emission of $\mathrm{CH}_{4}, \mathrm{~N}_{2} \mathrm{O}$ and $\mathrm{CO}_{2}$ to the global stock of GHGs that warms the environment and subsequently lead to climate change. Climate change on the other hand occurs as a result of the concentrations of these emitted gases in the atmosphere which cause alteration in a number of factors that in turn affect the productivity of cultivated crops.

This relationship which is self-reinforcing and self-perpetuating is captured in the schema below:

Figure 1 reveals that in the bid for farmers to cultivate food crops to meet their food requirements through interaction with land resources, they contribute to climate change problems and climate change in turn leaves negative effects on the ecosystem that affect crop production.

Crop production activities are very essential to the survival of farmers and other households in Nigeria. Any decision to stop crop production activities of farmers on the basis of the emission of GHGs is suicidal hence, the need to adopt measures that could keep low the emission of these gases in their crop production enterprises.

\section{Climate Change Mitigation Measures for Improved Crop Production}

Climate change mitigation involves measures that reduce the amount of emission or enhance the absorption capacity of greenhouse gases. Measures which could enhance the mitigation of climate change and encourage the crop production include; carbon sequestration, use of bio-energy, farm level mitigation approaches.

\subsection{Carbon Sequestration}

Sequestration activities enhance and preserve carbon sinks and include practices that store carbon through crop

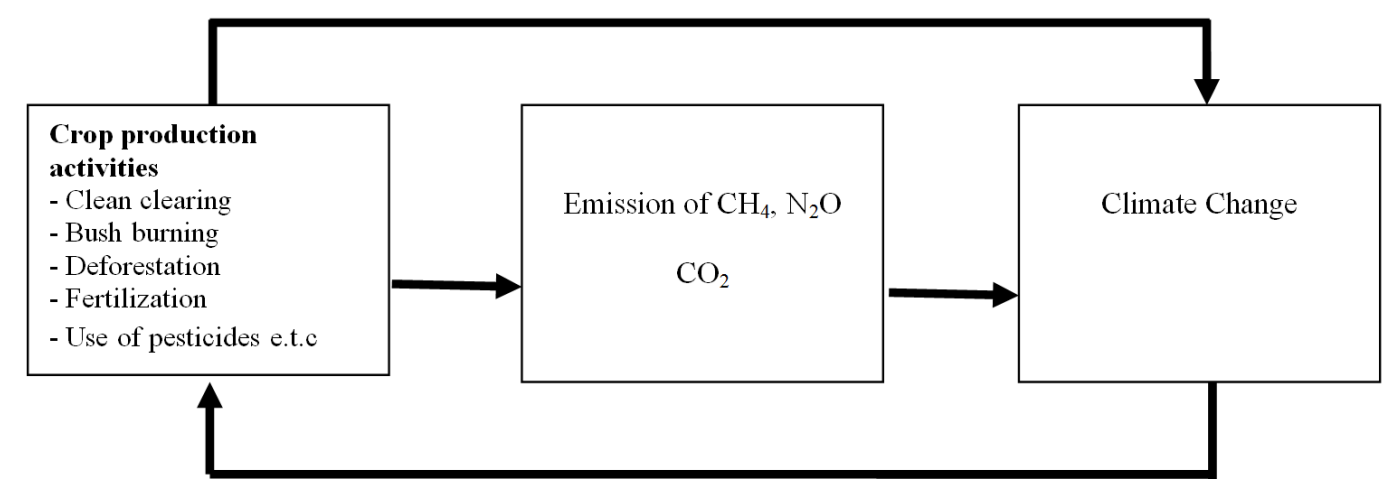

Figure 1. Linkages between crop production and climate change. 
land management "best practices" such as no-till agriculture, or slow the amount of stored carbon released into the atmosphere through burning, tillage and soil erosion. Sequestered carbon is stored in soils, resulting in increases in soil organic carbon (SOC). Reference [14] reported that sequestration accounts for 89 percent of the technical mitigation potential in agriculture compared to 11 percent for emission abatement. The authors explained that "best" management practices in agriculture such as reducing the amount of bare fallow, restoring degraded soils, improving pastures and grazing land, irrigation, crop and forage rotation, and no tillage practices can raise SOC. Sequestration of carbon thus, addresses the build of GHG in the atmosphere that contributes to climate change.

\subsection{Bio-Energy}

The production of liquid fuels from dedicated energy crop, such as grains and oilseed is to be re-examined in response to concerns over the environmental sustainability of continued fossil fuel dependence. The potential of bio-fuels to reduce carbon emissions, however, is highly dependent upon the nature of the production process through which they are manufactured and cultivated. A shift in this direction is capable of reducing the emission of carbon thereby keeping climate change problem low to support the production of food crops in Nigeria.

\subsection{Farm Level Mitigation Approaches}

Improved management practices that reduce on-farm emissions and enhance crop production include livestock manure management, fertilizer management, avoidance of bush burning, minimum tillage among others.

\subsection{Livestock and Manure Management}

Methods to reduce methane emissions from enteric fermentation include enhancing the efficiency of digestion with improved feeding practices and dietary additives. The efficacy of these methods depends on the quality of feeds, livestock breeds and age, and whether the livestock is grazing or stall-fed. Reference [9] observed that developing countries provide lower quality feed to livestock, which raises the emission rate per animal over that for developed country herds.

In livestock manure management, cooling and using solid covers for solid tanks and lagoons, separating solid from slurry, and capturing the methane emitted are relevant techniques. In developing countries in general and Nigeria in particular, applying this sort of manure management may be difficult as animal excretion happens in the field. Composting manure should be alternatives to reduce emissions.

\subsection{Fertilizer Management}

Improving the efficiency of fertilizer application or switching to organic production can decrease the amount of nutrient load and $\mathrm{N}_{2} \mathrm{O}$ emissions. However, overall benefits would need to be weighed against the potential impact on yield. Reference [15] revealed that fertilizer reductions of 90 percent in rain-fed maize field have been shown to reduce yield by 8.4 and 10.5 percent over the baseline in Brazil and China respectively. Furthermore, lack of access to soil nutrients needed for improving the quality of degraded soils is a hindrance to achieving food security is many parts of the developing world. Adequate consideration should be given to food security index in efficiency of fertilizers application or organic manure usage to ensure that the technique does not add to the national food insecurity question.

\subsection{Avoidance of Bush Burning}

Bush burning as a traditional practice of clearing the farm land contributes to the emission of GHGs such as $\mathrm{CO}_{2}$ and $\mathrm{CH}_{4}$ which adds to the atmospheric stock of gases thus, increasing global climate change. There is need to abolish the practice of bush burning and the emission of gases that result from the process. This could be achieved through clearing and raking of the grasses with the use of farm tools or alternatively allowing the grasses to decompose and increase the fertility of the soil. A soil that is fertile would ensure the release of nutrients for better production of crops. Equally, prohibition and punishment of defaulting farmers could serve as a deterrent to others in the habit of bush burning thus, reducing the atmospheric stock of $\mathrm{CO}_{2}$ and $\mathrm{CH}_{4}$. 


\subsection{Avoidance of Deforestation}

Deforestation is the cutting down of tress without replacement for urban development, or erection of buildings causes disequilibrium in the carbon-oxygen balance in nature. This imbalance leaves substantial amount of $\mathrm{CO}_{2}$ in the atmosphere which adds to the global stock of GHGs that fuel climate change problems affecting crop production. A shift from this practice through legislation and enlightenment can improve the carbon-oxygen balance thus reducing the stock of $\mathrm{CO}_{2}$ in the atmosphere. Low emission of $\mathrm{CO}_{2}$ reduces global climate change and its attendant effects on crop production.

\subsection{Adoption of Appropriate Tillage Practices}

Tillage operations of farmers speed up the release of stored soil organic carbon into the atmosphere that contribute to global climate change. The adoption of appropriate tillage operations such as zero or minimum tillage can sequester soil organic carbon and reduce its release to the atmosphere to add to the existing stock of gases. Good tillage practices further check soil erosion and associated dangers thereby conserving soil nutrients for greater yields of crops which would in turn address the food insecurity of the nation.

\section{Mitigation and Adaptation to Climate Change: The Role of Government}

It has been stressed that global climate change has devastating effects that are beyond the capability of resource poor farmers. There is every need for government to be actively involved in the mitigation and adaptation to global climate change by Nigerians. This could be achieved through the following:

\subsection{Design and Implementation of Good Overall Development Policies and Programmes}

Given the current uncertainty about location and specific effects of climate change, good development policies and programmes are among the best climate change adaptation investments. A pro-growth, proper development agenda that support agricultural sustainability also contributes to food security and climate change adaptation in Nigeria. Adaptation to climate change is easier when individuals have more resources and operate in an economic environment that is flexible and responsive.

\subsection{Increased Investment in Agricultural Productivity}

Even without climate change, greater investment in agricultural science and technology are needed to meet the ever increasing population of Nigerians. Agricultural science and technology solutions are essential to meet these demands.

Climate change places new and more challenging demand on agricultural productivity. Crop productivity enhancing research, including biotechnology will be essential to overcome stresses due to climate change. Crops do reasonably well in a range of production environment rather than extremely well in a narrow set of climate conditions. Research on changes in irrigation management practices is needed to reduce $\mathrm{CH}_{4}$ emissions and ought to be sponsored by the government at all levels.

One of the key lessons of Green Revolution is that improved agricultural productivity, even if not targeted at the poorest of the poor can be a powerful mechanism for alleviating poverty indirectly creating jobs and lowering food prices. Productivity enhancements that increase farmers' resilience in the face of climate change pressures will likely have similar poverty-reducing effects.

Rural infrastructure is essential if farmers are to take advantage of improved crop varieties and managements techniques. Higher yields and more cropped areas require maintaining and increasing the density of rural road networks to increase access to markets and reduce transaction costs. Investments in irrigation infrastructure are also needed, especially to improve the efficiency of water use.

\subsection{Reinvigoration of National Research and Extension Programmes}

Collaboration with local farmers, input suppliers traders and consumer groups are essentials for effective development and dissemination of locally appropriate cost effective techniques and cultivars to help revitalize communication among farmers, scientists and other stakeholders to meet the challenges of climate change. Such interactions make farmers to become aware of their activities that contribute to the emission of GHGs that fuel 
climate change and its consequences. This guides farmers towards good use and management of the natural resource base. Policies should be positioned to encourage extension agent reside in the rural communities and proffer instantaneous solutions to farmers' problems.

Extension services that specifically address climate change adaptation should include disseminating local cultivars of drought resistant crop varieties, teaching improved management systems and gathering information to facilitate national research work. Farmer organizations can be effective information-sharing mechanism and have potentials to provide cost effective links between government efforts and farmer activities.

\subsection{Improvement of Global Data Collection, Dissemination and Analysis}

Climate change, no doubt, has dramatic consequences for agriculture and uncertainty remains about where the effects will be greatest. These uncertainties make it challenging to move forward on policies to control the effects of climate change. Global efforts to collect and disseminate data on the spatial nature of agriculture need to be strengthened. Regular observations of the surface of the earth via remote sensing are critical. Funding for national statistical programme should be increased so that they can fulfill the task of monitoring global change. Understanding agriculture climate interactions well enough to support mitigation activities based on land use requires major improvements in data collection, dissemination and analysis.

\subsection{Recognizing the Relationship between Enhanced Food Security and Climate Change Mitigation}

Climate change poses huge challenges to food security efforts and any activity that supports agricultural adaptation also enhances food security. Conversely, anything that results in increased food security will provide the poor, especially the rural poor, with the resources that will help them adapt to climate change.

\subsection{Lending Support for Community-Based Climate Change Adaptation Strategies}

Crop productivity, market access and the effects of climate are location specific. International development agencies and national government should work to ensure that technical financial and capacity-building support reaches local communities. They should also encourage community participation in national adaptation planning processes. Community based adaptation strategies can help rural communities to strengthen their capacity to cope with disasters and improve their livelihoods. While national adaptation policies and strategies are important, the implementation of these strategies at the local level will be the ultimate test of the effectiveness of the adaptation.

\subsection{Funding of Climate Chang Adaptation Programme}

National budgetary allocation for climate change adaptation and other disasters should be substantially increased to cope with the challenges whenever they occur. The current situation in Nigeria which led to supplementary budgetary provisions to take care of flood victims occasioned by climate change is not a welcome development. Nigerian government and other developing countries of the world should budget and reserve good amount of money in the treasuries for ecological challenges that occur without prior information. Furthermore, such budgetary provisions can also be used to procure equipment for investment in irrigation, rural infrastructure and research.

\section{Conclusion and Recommendations}

The challenges posed by climate change on crop production and the need to mitigate the problem necessitated this paper. Climate change catastrophe which is the concentration of GHGs is caused by economic activities, such as industrial development transportation and agricultural production activities, has both direct and indirect consequences on crop production. These effects which are most negative threaten crop productivity hence, the need to adopt measures that are sustainable and emit less GHGs in crop production enterprises and policy provisions strengthened to address the challenges in Nigeria. The paper recommended that:

1) Only agricultural production technologies that have potentials to reduce the emission of GHG should be adopted in crop production.

2) Sustainable development cultures in agriculture should be given priority and agriculture should not be seen 
as "business as usual".

3) Government should be proactive in their policies to be ready for ecological challenges that occur mostly unplanned.

4) Ecological funds should be raised as the magnitude of ecological disasters is usually not certain and difficult to control.

\section{References}

[1] Kassie, M. and Zikhali, P. (2009) Brief on Sustainable Agriculture. The Expert Group Meeting on Sustainable Land Management and Agricultural Practices in Africa: Bridging the Gap between Research and Farmers, 16-17 April 2009.

[2] Pingali, P.I. and Rosegrant, M.W. (1994) Confronting the Environmental Consequences of Green Revolution in Asia. Environment and Production Technology Division Discussion Paper No. 2. International Food Policy Research Institute, Washington DC.

[3] FAO (2008) The State of Food Insecurity in the World: High Food Prices and Food Security Threats and Opportunities. FAO, Rome.

[4] Huber, D. and Gulledge, J. (2011) Extreme Weather and Climate Change. Understanding the Link, Managing the Risks. Extreme Weather Web Page.

[5] Bernard, A. (2012) Climate Change-Meaning, Implication, Suggested Solutions. http://www.climate.suggestion.php/com

[6] Chikaire, J., Nnadi, F.N., Orusha, J.O. and Onogu, B. (2012) Integrating Climate Change Issues into Agricultural Education, Teaching and Learning in Nigeria. Advances in Agriculture Sciences and Engineering Research, 2, 115-127.

[7] Stern, N. (2014) Economics of Climate Change: A Review. www.hmtreasury.gove.uk.independent-review-economic-climate-change/sterm-review-report.fm

[8] World Health Organization (1996) Food Security. http://www.nal.unep/org/foodsecurity

[9] Mark, W.S., Mandy, E., Gray, Y., Lan, B., Saleemul, H. and Rowena, V. (2008) Climate Change and Agriculture: Treats and Opportunities. German (Germany) Technische Zusammenarbeit (GTZ) GmbH, Deutsche Gesellsechaft Fur.

[10] World Research Institute (2008) Climate Analysis Indicators Toolkit. http://cait.wri.org/

[11] USEPA (2006) Global Mitigation of Non- $\mathrm{CO}_{2}$ Greenhouse Gases. Office of Atmospheric Programmes, Washington DC.

[12] IPCC (2007) Summary for Policy Makers, Climate Change 2007: Synthesis Report. Fourth Assessment Report of the Intergovernmental Panel for Climate Change. http://www.ipcc.ch/pdfassessment-report/ar4/syer/ar4-syr-spm.pdf

[13] IAASTD (2008) Executive Summary of the Synthesis Report of the International Assessment of Agricultural Knowledge Science and Technology for Development (IAASTD).

[14] Smith, P.D., Martno, Z., Cai, D., Gwary, H., Janzen, P., Kumar, B., McCarl, S., Ogle, F., O Mara, C. and Rice, B.C. and Scholes (2007) Agriculture. In: Metz, B., Davidson, O.R., Bosch, P.R., Dave, R. and Meyer, L.A., Eds., Climate Change 2007: Mitigation. Contribution of Working Group III to the Fourth Assessment Report of Inter-Governmental Panel on Climate Change, Cambridge University Press, New York.

[15] IPCC (2007) Impact Adaptation and Vulnerability: Contributions of Working Group 11 to the Fourth Assessment Report of the IPCC. IPCC, Switzerland. 
Scientific Research Publishing (SCIRP) is one of the largest Open Access journal publishers. It is currently publishing more than 200 open access, online, peer-reviewed journals covering a wide range of academic disciplines. SCIRP serves the worldwide academic communities and contributes to the progress and application of science with its publication.

Other selected journals from SCIRP are listed as below. Submit your manuscript to us via either submit@scirp.org or Online Submission Portal.
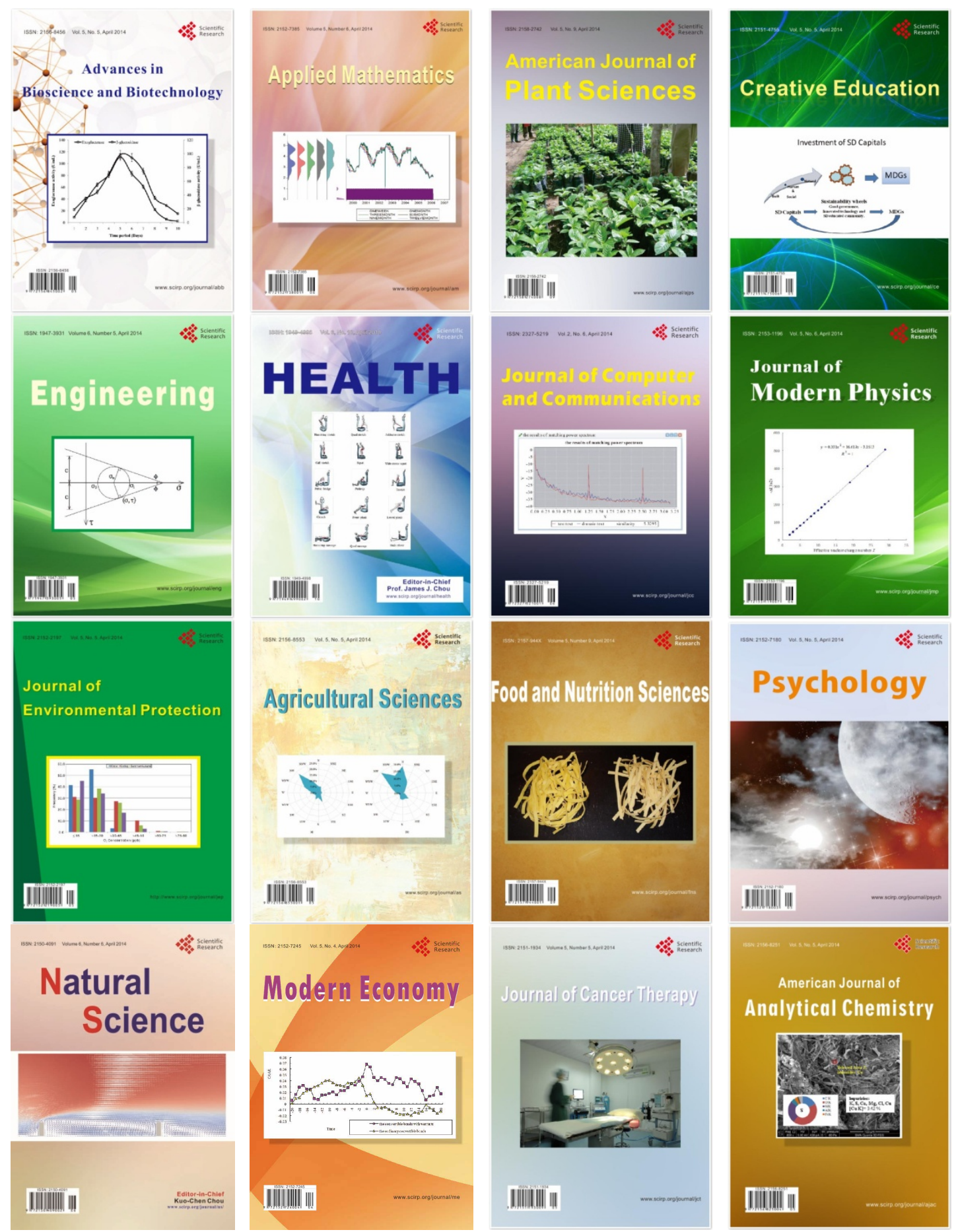